\title{
Sağlık kurumlarının ve eczanelerin taleplerine yönelik ecza deposu yer seçimi problemi
}

\author{
Pharmaceutical warehouse site selection problem considering the demands of medical \\ institutions and pharmacies
}

\author{
Aslıhan YILDIZ*1,a, Selin SONER KARA ${ }^{1, b}$, Coşkun ÖZKAN ${ }^{1, c}$ \\ ${ }^{1}$ Yıldız Teknik Üniversitesi, Makine Fakültesi, Endüstri Mühendisliği Bölümü, 34349, İstanbul
}

• Geliş tarihi / Received: 17.01.2020 • Düzeltilerek geliş tarihi / Received in revised form: 22.02.2021 • Kabul tarihi / Accepted: 08.03 .2021

$\ddot{O} z$

Sağllk sektöründe ecza ürünlerinin üreticiden son tüketiciye ivedi bir şekilde temin edilmesi son derece önemlidir. Sektörün tedarik ağının karmaşık yapıda olması, ecza ürünlerinin dağıtımı çalışmalarına araştırmacıların ilgisinin artmasını sağlamıştır. Çalışmada ecza ürünlerinin dağıtımını içeren tedarik ağında, farklı yapılardaki talep noktaları için ecza deposu yeri seçim problemi ele alınmıştır. Bu bağlamda problem, kapasiteli tesis yeri seçim problemi olarak ele alınmış ve probleme yönelik yeni bir matematiksel model önerilmiştir. Hazırlanan model için uygulama bölgesi olarak İstanbul/Silivri ilçesi seçilmiştir. Çalışmanın devamında önerilen matematiksel model kullanılarak minimum mesafeyle dağıtım yapılması için açılması gereken ecza depolarının yerleri belirlenmiştir. Modelin sonuçlarını analiz etmek ve doğruluğunu göstermek amacıyla problemde kullanılan parametre değerleri değiştirilerek duyarlılık analizi yapılmıştır. Sonuçlar duyarlılık analizi ile birlikte sunulmuştur.

Anahtar kelimeler: Ecza deposu, Karışık tam sayılı programlama, Yer seçimi

\begin{abstract}
It is extremely important that pharmaceutical products are effectively supplied from the producer to the end consumer in the health sector, The complexity of the supply network of the sector has increased the interest of researchers in the distribution of pharmaceutical products. In this study, site selection problem for pharmaceutical warehouse for the demand points of different structures is discussed in the supply network, which includes the distribution of pharmaceutical products, In this context, the problem is considered as the capacited site selection problem and a novel mathematical model is proposed for the problem. Istanbul / Silivri district is chosen as the application area for the proposed mode. After, the sites of the pharmaceutical warehouses that should be opened in order to distribute with minimum distance were determined using the proposed mathematical model. Sensitivity analysis is performed by changing the parameter values used in the problem in order to analyze the results of the model and to demonstrate its accuracy. The results are presented with sensitivity analysis.
\end{abstract}

Keywords: Pharmaceutical warehouse, Mixed integer programming, Site selection

\footnotetext{
*a Aslıhan YILDIZ; aslihany@yildiz.edu.tr, Tel: (0212) 38328 65, orcid.org/0000-0001-5288-7967

${ }^{\mathrm{b}}$ orcid.org/0000-0002-0894-0772 $\quad{ }^{\mathrm{c}}$ orcid.org/0000-0002-0318-8614
} 


\section{Giriş}

Sağl1k sektörü içerisinde ecza ürünlerinin tedarik edilmesi sürecinde, bu ürünlerin etkin bir şekilde talep noktalarına ulaştırılması kritik öneme sahiptir. Son yıllarda kamu ve özel şirketler ecza ürünlerinin tedarik zincirinin çevikliğini, esnekliğini ve güvenirliğini artırmak için büyük efor sarf etmektedirler (Myerson vd., 2015). Bununla birlikte, değişen talep noktalarının tedarik zinciri stratejisi üzerinde doğrudan etkileri olabilir. Genellikle ecza ürünlerinin insanlara ulaşımı tek bir nokta yerine, farklı yapılardaki noktalarda gerçekleşebilmektedir. $\mathrm{Bu}$ durum dikkate alındığında, tedarik ağının etkin bir şekilde yönetilmesini gerektirmektedir. Ecza ürünlerinin tedariği sürecinde, herhangi bir aşamada meydana gelebilecek olan bir problem, insan ve toplum sağlığını olumsuz yönde etkileyecek ciddi bir risk oluşturabilir (Friemann ve Schönsleben, 2016). Ecza ürünleri tedarik zincirinin sağlık açısından önemli olması ve kompleks yapısından dolayı birçok çalışmaya konu olmuştur.

Papageorgiou vd. (2001) ilaç şirketleri için geliştirdikleri karma tam sayılı matematiksel modele ürün geliştirme, tanıtım stratejileri ve kapasite planlama gibi bileşenleri dahil ederek ecza ürünleri tedarik zincirini modellemişlerdir. Shah (2004) çalışmasında ecza ürünleri tedarik ağında optimizasyon yaparken dikkat edilmesi önemli konulara ve stratejilere değinmiştir. Pedroso ve Nakano (2009) tüketicilerin ilaç alırken doktor bilgisi dahilinde karar verdiğini gözeterek, ecza ürünleri tedarik ağında bilgi akışının nasıl olması gerektiği hakkında çalışmışlardır. Yu vd. (2010) Çin'deki ecza ürünleri tedarik zincirini inceledikleri çalışmalarında, zincirin performansını ve çarpıklıklarını belirlemişlerdir. Bazı reformlar önererek bunların politik sonuçlarını tartışmışlardır. Rosetti vd. (2011) biyofarmasötik ilaçların tedarik zinciri boyunca satın alma, dağıtım ve satılma şeklini değiştiren önemli bileşenleri tanımlamış ve incelemişlerdir. Masoumi vd. (2012) varyasyonel eşitsizlik teorisi kullanarak ecza ürünlerinin tedarik zincirleri için genelleştirilmiş bir oligopol modeli önermişlerdir. Uthayakumar ve Priyan (2013) çoklu ecza ürününün değişken teslim süresini, izin verilen ödeme gecikmelerini, alan kullanılabilirliğine ilişkin kısıtlamaları ve müşteri hizmet düzeyini dikkate alan ve bir ilaç şirketi ve bir hastane tedarik zincirini içeren tedarik zinciri için envanter modeli önermişlerdir. Weraikat vd. (2016) gerçek ecza ürünleri tedarik zincirinde tersine lojistik için etkin bir koordinasyon modeli önemişlerdir. Nematollahi vd. (2017) iki aşamalı ecza ürünleri tedarik zincirlerini incelemişlerdir. Üyelerin iş birlikleri üzerine kurguladıkları modelde tedarik zincirindeki doluluk oranını maksimize etmeyi amaçlamışlardır. Zahiri vd. (2018) ecza ürünlerinin bozulabilir olmasını, ikame edilebilirliğini ve toplu alımdaki indirimleri dikkate alan, belirsizlik içeren bir matematiksel model geliştirmişlerdir. Chen vd. (2019) çalışmalarında tavan fiyat uygulamasının ecza ürünleri üreticisi üzerindeki etkilerini araştırmışlardır. Haial vd. (2019) üç aşamalı olarak ele aldıkları ecza ürünleri tedarik zincirinde, en uygun ağ yapısını çok kriterli karar verme yöntemleri ile belirlemişlerdir. Ji (2019) hastanelerden ve eczanelerden hastaya ilaç dağıtımı problemini ela almıştır. Zaman pencereli araç rotalama problemi olarak modellemiş ve en uygun rotayı belirlemiştir. Bahadori-Chinibelagh vd. (2019) çok sayıda ecza deposunun bulunduğu bir ilaç dağıtım problemini çok depolu araç rotalama problemi olarak ele almış ve geliştirdikleri algoritmaları kullanarak problemi çözmüşlerdir. Lubis ve Mawengkang (2020) ecza deposundan hastaların evlerine ilaç dağıtım problemini, farklı kapasiteli araç rotalama problemi olarak modellemişlerdir. Redi vd. (2020) kapasiteli araç rotalama problemi olarak modelledikleri ilaç dağıtım problemini benzetimli tavlama algoritması kullanarak çözmüşlerdir.

Yapılan çalışmada hastanelere, sağlık ocaklarına ve eczanelere ilaç dağıtımına yönelik ecza deposu yeri seçim problemi ele alınmıştır. Literatür incelendiğinde, ecza ürünlerinin talep noktalarına hızlı ve etkin bir şekilde dağıtımını amaçlayan en uygun depo yeri seçimi probleminin yeni bir çalışma alanı olduğu söylenebilir. Hızlı bozulabilen ve duyulan ihtiyacın önemi göz önüne alındığında, ilaç dağıtımının efektif olarak planlanması çok önemlidir. Hastaların ilaç tedariği için en sik başvurduğu kurumlar olan hastaneler, sağlık ocakları ve eczaneler dikkate alınarak; yapılan bu çalışma kapsamında ecza deposundan sağlanan ilaçların dağıtımı gözetilerek belirlenen noktalar arasından ecza deposu için en uygun noktanın belirlenmesi amaçlanmıştır.

Çalışma şu şekilde düzenlenmiştir: İkinci bölümde, geleneksel tesis yeri seçim problemi ve kapasiteli tesis yeri seçim problemi özetlenmiştir. Daha sonra çalışma kapsamında ele alınan problem için önerilen matematiksel model ayrıntılarıyla verilmiştir. Üçüncü bölümde İstanbul/Silivri ilçesi için yapılan uygulama açıklanmıştır. Dördüncü bölümde duyarlılı analizi yardımıla matematiksel modelin etkinliği test edilmiştir. Son bölümde ise, sonuçlara ve gelecekteki çalışmalara yönelik bilgiler verilmiştir. 


\section{Tesis yeri seçim problemi}

Belirli bir bölgede müşterilere ürün dağıtmak veya belirli hizmetleri sunmak için aynı türde birden fazla tesis bulunabilmektedir. Bu gibi yapilarda, karar vericiler, müşteriye hızlı ulaşmayı sağlamanın yanı sıra, maliyetleri de dikkate alarak tesis konumlarını seçmelidir. Bu bağlamda, tesis yeri seçim problemi, ilgili temel sorunları dikkate alan kombinatoryal bir problemdir.

Her tesis tarafindan sağlanan ürün / hizmet miktarına ilişkin kapasitelerin varlığına bağlı olarak iki tür tesis yeri seçim problemi vardır. Tesis kapasitesinin dahil edildiği, sınırlı miktarda ürün / hizmet sağlama durumunun olduğu tesis yeri problemlerine kapasiteli tesis yeri problemi denir. Öte yandan, her müşteri en uygun gibi görünen (genellikle en yakın) herhangi bir tesisten hizmet alabiliyorsa, yani her tesis sinırsiz miktarda hizmet sunma kapasitesine sahipse, bu tip problemlere kapasitesiz tesis yeri seçim problemi denir. Her iki tip problem için uygun çözümlerin sayısı, örneklem büyüklügü ile birlikte üstel olarak artar. Gerçek hayat problemlerinde çoğu zaman büyük boyutlu problemlere çözüm getirme durumu olduğundan, en uygun çözümleri bulmak oldukça zordur. Yukarıda bahsedilen iki tip tesis yeri seçim probleminin de NP-Zor olduğu bilinmektedir. Bu tip problemlere yönelik en uygun çözümleri verimli bir şekilde bulmak için algoritmalar yetersiz kalmaktadır (Balinski, 1965; Wong et al., 2010). Literatürde çok farklı şekillerde ele alınan (Arthur vd., 1997; Haight vd., 2000; Li vd., 2009; Jelokhani-Niaraki ve Malczewski, 2015; Koc vd., 2019) tesis yeri seçimi problemlerinde, farklı çözüm yolları (Oufella ve Hamdadou, 2019; Yap vd. 2019; Wu vd., 2019; Lin vd., 2020) önerilmiştir.

\subsection{Kapasiteli tesis yeri seçim problemi}

Yapılan bu çalışmada kapasiteli tesis yeri seçim probleminin bir uzantısına odaklanılmıştır. Geleneksel kapasiteli tesis yeri seçim probleminde, problem $\mathrm{G}=(\mathrm{N}, \mathrm{A})$ olarak ifade edilen yönsüz bir graf üzerinde tanımlanmıştır, burada $\mathrm{N}$ ile graf üzerinde yer alan dügümler kümesi, A ile de düğümler arasındaki bağlantılar kümesi temsil edilmiştir. Her bir müşteri aday tesis olarak ifade edilmiş ve düğümler arasındaki bağlantılar $\mathrm{A}=$ $\{(\mathrm{i}, \mathrm{j}): \forall \mathrm{i}, \mathrm{j} \in \mathrm{N}, \mathrm{i} \neq \mathrm{j}\}$ kümesinde tanımlanmıştır. Mevcut durumda ürünlerin müşterilere dağıtımında, kullanılacak araçlar için izlenecek yolların açık olduğu varsayılmıştır. Araçların düğümler arasında kat ettiği mesafenin (dij) negatif olamayacağ 1 ve $d_{i j}=d_{j i}$ olduğu varsayılmıştır. Her bir müşterinin talebi vardır. Açılacak tesisler sınırlı kapasiteye sahiptir. Tesisler kapasitesini aşmayacak şekilde hizmet verebilmektedir. Aday düğümler içinden tesis açılacak olan düğümlerin belirlenmesi amaçlanmaktadır.

Her bir tesis için tesis açma (kurulum) maliyeti $F_{i}$ vardır. Tesis açma maliyetine ek olarak tesis i den müşteri j ye mesafeyle doğru orantılı ürün taşıma maliyeti $d_{i j}$ vardır. Her müşteri yalnızca bir tesise atanmalıdır. Açılan tesise atanacak müşteri sayısında bir kısıtlama yoktur. Açılan tesis, kapasitesini aşmayacak şekilde sınırsız sayıda müşteriye hizmet verebilir. $\mathrm{Bu}$ bağlamda, kapasiteli tesis yeri seçim probleminde, tesis açma ve taşıma maliyetlerinin toplamının en küçüklenmesi amaçlanmaktadır. Problemin matematiksel modeli aşağıda verilmiştir.

\section{Setler}

I Tüm müşteri noktaları

\section{Parametreler}

$\mathrm{d}_{\mathrm{ij}} \quad$ Noktalar arasındaki geçiş mesafeleri $(\mathrm{i}, \mathrm{j} \in \mathrm{I})$

$\mathrm{F}_{\mathrm{i}} \quad$ Tesis açma maliyeti $(\mathrm{i} \in \mathrm{I})$

$\mathrm{t}_{\mathrm{i}} \quad$ Talep $(\mathrm{i} \in \mathrm{I})$

$\mathrm{C}_{\mathrm{i}} \quad$ Kapasite $(\mathrm{i} \in \mathrm{I})$

\section{Karar Değişkenleri}

$$
\begin{aligned}
& Y_{i}\left\{\begin{array}{l}
1, \text { eğer nokta i'ye tesis açılırsa; } \\
0, \quad \text { diğer durumlar }
\end{array}\right. \\
& \mathrm{X}_{\mathrm{ij}}\left\{\begin{array}{l}
1, \text { eğer nokta j, nokta i'den hizmet alırsa; } \\
0, \quad \text { diğer durumlar }
\end{array}\right.
\end{aligned}
$$

\section{Formülasyon}

$$
\min \sum_{i} F_{i} Y_{i}+\sum_{i} \sum_{j} X_{i j} d_{i j}
$$

s.t.

$$
\begin{array}{ll}
\sum_{\mathrm{i}} \mathrm{X}_{\mathrm{ij}}=1 & (\forall \mathrm{j} \in \mathrm{I}) \\
\sum_{\mathrm{i}} \mathrm{t}_{\mathrm{i}} \mathrm{X}_{\mathrm{ij}} \leq \mathrm{C}_{\mathrm{j}} \mathrm{Y}_{\mathrm{j}} & (\forall \mathrm{j} \in \mathrm{I}) \\
\mathrm{X}_{\mathrm{ij}} \leq \mathrm{Y}_{\mathrm{i}} & (\forall \mathrm{i}, \mathrm{j} \in \mathrm{I}) \\
\mathrm{Y}_{\mathrm{i}}, \mathrm{X}_{\mathrm{ij}} \in\{0,1\} & (\forall \mathrm{i}, \mathrm{j} \in \mathrm{I})
\end{array}
$$

Amaç fonksiyonu (1) olarak, tesis açma $\left(\sum_{\mathrm{i}} \mathrm{F}_{\mathrm{i}} \mathrm{Y}_{\mathrm{i}}\right)$ ve taşıma $\left(\sum_{\mathrm{i}} \sum_{\mathrm{j}} \mathrm{X}_{\mathrm{ij}} \mathrm{d}_{\mathrm{ij}}\right)$ maliyet bileşenlerinden oluşan toplam maliyetin en küçüklenmesi amaçlanmıştır. Kısıt (2) ile her bir müşterinin yalnızca bir tesisten hizmet alması sağlanmaktadır. Kısıt (3) ile açılan tesisten, tesisin kapasitesini 
aşmayacak şekilde hizmet verilmesi sağlanmıştır. Kısıt (4) açılmayan tesislerden hizmet verilmesini engellemektedir. Son olarak Kisit (5) ile karar değişkenlerinin 0 ya da 1 değerini alması sağlanmaktadır.

\subsection{Sağlık kurumlarının ve eczanelerin taleplerine yönelik ecza deposu yer seçimi problemi}

Sağllk sektörü içerisinde ecza ürünlerinin tedarik edilmesi sürecinde, bu ürünlerin etkin bir şekilde talep noktalarına ulaştırılması kritik öneme sahiptir. Dolayısıyla ecza ürünleri gibi yaşamsal etkiye sahip acil ihtiyaçların dağıtım sürecinin iyi bir şekilde yönetilmesi gerekir. Bu bağlamda, çalışma kapsamında bu ürünlerin ecza depolarından, hastanelere, sağlık ocaklarına ve eczanelere dağıtılması sürecinde en uygun depo yeri seçimi problemi ele alınmıştır.

Ele alınan problemde, ürünlerin talep noktalarına ulaştırılma süresinin minimize edilmesi

\section{Parametreler}

$\mathrm{G}_{\mathrm{h}}^{1} \quad$ Hastanelerin talebi $(\mathrm{h} \in \mathrm{H})$

$\mathrm{G}_{\mathrm{s}}^{2} \quad$ Sağlık ocaklarının talebi $(\mathrm{s} \in \mathrm{S})$

$\mathrm{G}_{\mathrm{e}}^{3} \quad$ Eczanelerin talebi $(\mathrm{e} \in \mathrm{E})$

$\mathrm{t}_{\mathrm{ih}}^{1} \quad$ Aday noktalardan hastanelere geçiş süreleri ( $\mathrm{i} \in \mathrm{I}, \mathrm{h} \in \mathrm{H}$ )

$\mathrm{t}_{\mathrm{is}}^{2} \quad$ Aday noktalardan sağlık ocaklarına geçiş süreleri $(\mathrm{i} \in \mathrm{I}, \mathrm{s} \in \mathrm{S})$

$\mathrm{t}_{\mathrm{ie}}^{3} \quad$ Aday noktalardan eczanelere geçiş süreleri (i $\in \mathrm{I}, \mathrm{e} \in \mathrm{E}$ )

$\mathrm{d}_{\mathrm{ih}}^{1} \quad$ Aday noktalardan hastanelere mesafe $(\mathrm{i} \in \mathrm{I}, \mathrm{h} \in \mathrm{H})$

$\mathrm{d}_{\mathrm{is}}^{2} \quad$ Aday noktalardan sağlık ocaklarına mesafe (i $\in \mathrm{I}, \mathrm{s} \in \mathrm{S}$ )

$\mathrm{d}_{\mathrm{ie}}^{3} \quad$ Aday noktalardan eczanelere mesafe $(\mathrm{i} \in \mathrm{I}, \mathrm{e} \in \mathrm{E}$ )

$\mathrm{C}_{\mathrm{i}} \quad$ Aday depo kapasitesi $(\mathrm{i} \in \mathrm{I})$

$\mathrm{FC}_{\mathrm{i}} \quad$ Aday depo açma maliyeti ( $\left.\mathrm{i} \in \mathrm{I}\right)$

PI Açılacak tesis sayısı

$\mathrm{N}_{\mathrm{i}}^{1} \quad$ Depodan hizmet verilebilecek maksimum hastane sayısı $(\mathrm{i} \in \mathrm{I})$

$\mathrm{N}_{\mathrm{i}}^{2} \quad$ Depodan hizmet verilebilecek maksimum sağlık ocağı sayısı $(\mathrm{i} \in \mathrm{I})$

$\mathrm{N}_{\mathrm{i}}^{3} \quad$ Depodan hizmet verilebilecek maksimum eczane sayısı $(\mathrm{i} \in \mathrm{I}$ )

$\mathrm{N}_{\mathrm{i}}^{4} \quad$ Depodan hizmet verilebilecek maksimum müşteri sayısı (i $\in \mathrm{I}$ )

B Kullanılabilir bütçe

$\max ^{1} \quad$ Hastanelere en geç varılabilecek süre

$\max ^{2}$ Sağlık ocaklarına en geç varılabilecek süre

$\max ^{3} \quad$ Eczanelere en geç varılabilecek süre

M Yeterince büyük sayı

\section{Karar Değişkenleri}

$Y_{i}\{1$, eğer i'ye depo açlırsa;

0 , diğer durumlar

$\mathrm{Z}_{\mathrm{ih}}\left\{\begin{array}{l}1, \text { eğer aday } \mathrm{i}^{\prime} \text { den hastane } \mathrm{h}^{\prime} \text { ye hizmet verilirse; } \\ 0, \quad \text { diğer durumlar }\end{array}\right.$

$X_{\text {is }}\{1$, eğer aday i'den sağlık ocağı s'ye hizmet verilirse;

$X_{\text {is }}\{0$, diğer durumlar

$W_{\text {ie }}\left\{\begin{array}{l}1, \text { eğer aday i'den eczane e'ye hizmet verilirse; } \\ 0,\end{array}\right.$ 


\section{Formülasyon}

$\min \sum_{\mathrm{i}} \sum_{\mathrm{h}} \mathrm{d}_{\mathrm{ih}}^{1} \mathrm{Z}_{\mathrm{ih}}+\sum_{\mathrm{i}} \sum_{\mathrm{s}} \mathrm{d}_{\mathrm{is}}^{2} \mathrm{X}_{\mathrm{is}}+\sum_{\mathrm{i}} \sum_{\mathrm{e}} \mathrm{d}_{\mathrm{ie}}^{3} \mathrm{~W}_{\mathrm{ie}}$

s.t.

$\sum_{\mathrm{i}} \mathrm{Y}_{\mathrm{i}}=\mathrm{PI}$

$\sum_{\mathrm{i}} \mathrm{Y}_{\mathrm{i}} \mathrm{FC}_{\mathrm{i}} \leq \mathrm{B}$

$\sum_{\mathrm{i}} \mathrm{Z}_{\mathrm{ih}}=1$

$\sum_{\mathrm{i}} \mathrm{X}_{\mathrm{is}}=1$

$\sum_{\mathrm{i}} \mathrm{W}_{\mathrm{ie}}=1$

$\sum_{\mathrm{i}} \mathrm{t}_{\text {ih }}^{1} \mathrm{Z}_{\text {ih }} \leq \max ^{1}$

$\sum_{\mathrm{i}} \mathrm{t}_{\mathrm{is}}^{2} \mathrm{X}_{\mathrm{is}} \leq \max ^{2}$

$\sum_{\mathrm{i}} \mathrm{t}_{\mathrm{ie}}^{3} \mathrm{~W}_{\mathrm{ie}} \leq \max ^{3}$

$\mathrm{Z}_{\text {ih }} \leq \mathrm{Y}_{\mathrm{i}}$

$\mathrm{X}_{\text {is }} \leq \mathrm{Y}_{\mathrm{i}}$

$\mathrm{W}_{\mathrm{ie}} \leq \mathrm{Y}_{\mathrm{i}}$

$\sum_{\mathrm{h}} \mathrm{G}_{\mathrm{h}}^{1} \mathrm{Z}_{\mathrm{ih}}+\sum_{\mathrm{s}} \mathrm{G}_{\mathrm{h}}^{2} \mathrm{X}_{\mathrm{is}}+\sum_{\mathrm{e}} \mathrm{G}_{\mathrm{h}}^{3} \mathrm{~W}_{\mathrm{ie}} \leq \mathrm{C}_{\mathrm{i}} \mathrm{Y}_{\mathrm{i}}$

$\sum_{\mathrm{h}} \mathrm{Z}_{\mathrm{ih}} \leq \mathrm{N}_{\mathrm{i}}^{1}$

$\sum_{\mathrm{s}} \mathrm{X}_{\text {is }} \leq \mathrm{N}_{\mathrm{i}}^{2}$

$\sum_{\mathrm{e}} \mathrm{W}_{\mathrm{ie}} \leq \mathrm{N}_{\mathrm{i}}^{3}$

$\sum_{\mathrm{h}} \mathrm{Z}_{\mathrm{ih}}+\sum_{\mathrm{s}} \mathrm{X}_{\mathrm{is}}+\sum_{\mathrm{e}} \mathrm{W}_{\mathrm{ie}} \leq \mathrm{N}_{\mathrm{i}}^{4}$

$\mathrm{Y}_{\mathrm{i}}, \mathrm{Z}_{\mathrm{ih}}, \mathrm{X}_{\mathrm{is}}, \mathrm{W}_{\mathrm{ie}} \in\{0,1\}$

$(\forall \mathrm{h} \in \mathrm{H})$

$(\forall s \in S)$

$(\forall \mathrm{e} \in \mathrm{E})$

$(\forall \mathrm{h} \in \mathrm{H})$

$(\forall \mathrm{s} \in \mathrm{S})$

$(\forall \mathrm{e} \in \mathrm{E})$

$(\forall \mathrm{i} \in \mathrm{I}, \forall \mathrm{h} \in \mathrm{H})$

$(\forall i \in I, \forall s \in S)$

$(\forall \mathrm{i} \in \mathrm{I}, \forall \mathrm{e} \in \mathrm{E})$

$(\forall \mathrm{i} \in \mathrm{I})$

$(\forall \mathrm{i} \in \mathrm{I})$

$(\forall \mathrm{i} \in \mathrm{I})$

$(\forall \mathrm{i} \in \mathrm{I})$

$(\forall i \in I)$

$(\forall \mathrm{i} \in \mathrm{I}, \forall \mathrm{h} \in \mathrm{H}, \forall \mathrm{s} \in \mathrm{S}, \forall \mathrm{e} \in \mathrm{E})$

Ecza ürünlerinin hastane, sağlı ocakları ve eczanelere dağıtımına yönelik ele alınan ecza deposu yeri seçim problemi için önerilen matematiksel modelde kullanılan kısıtlar aşağıda açıklanmıştır.

(6) Ürünlerin toplam ulaştırılma mesafesini minimize eder.

(7) Belirlenmiş depo sayısı kadar depo açılabilir.

(8) Bütçe aşılamaz.

(9) Sirasıyla hastane, sağlı ocağ eczanelerin talepleri yalnızca bir noktadan karşılanmalıdır.

(10) Belirlenen en geç varış süresinden önce, sirasıyla hastane, sağlık ocağı ve eczanelerin talepleri karşılanmalıdır.

(11) Açılmayan depodan sırasıyla hastane, sağlık ocağı ve eczanelere hizmet verilemez.

(12) Aday depolar kapasitesinden fazla hizmet veremez.

(13) Önceden belirlenen hizmet miktarı kadar, aday depolardan hastane, sağlık ocağ 1 ve eczaneye hizmet verilebilir.

(14) Aday depodan en fazla belirtilen sayı kadar kurumlara hizmet verilebilir.

(15) Karar değişkenleri yalnızca 0 ya da 1 değerini alabilir.

\section{Uygulama}

Çalışmada ele alınan hastane, sağlık ocakları ve eczanelerin ecza ürünlerine olan ihtiyaçlarını karşılamaya yönelik depo yeri seçim problemi için, İstanbul / Silivri ilçesi seçilmiştir. Bölgenin demografik yapısı, ulaşım ağının zayıf olması ve

yerleşimin görece geniş bir alana yayılması, ilçenin seçilmesinde önemli rol oynamıştır.

\subsection{Verilerin belirlenmesi}

Çalı̧̧mada talep noktalarına minimum mesafeyle ürün dağıtımını sağlayacak en uygun ecza depo yeri seçimi amaçlanmıştır. $\mathrm{Bu}$ amaç dahilinde problemin çözümüne yönelik gereksinim duyulan veriler belirlenmiştir.

\subsubsection{Aday depo yerlerinin belirlenmesi}

İlçenin farklı bölgelerinden on farklı nokta, ecza depoları için aday noktalar olarak belirlenmiştir. Dört adet deponun kurulacağ belirlenen aday noktalar Şekil 1'de gösterilmiştir.

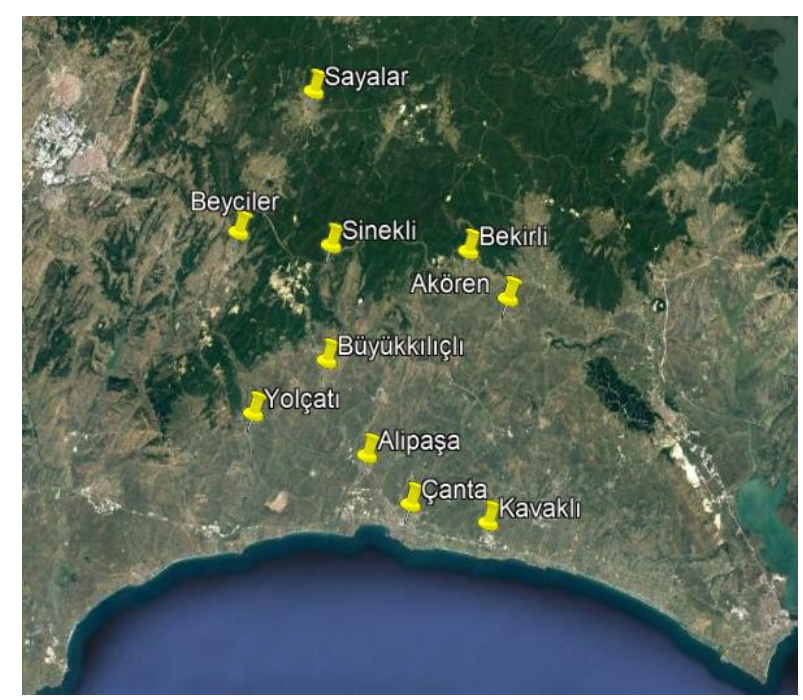

Şekil 1. Aday depo yerleri 
Aday noktaların belirlenmesinin ardından, bölgedeki arsa ve emlak fiyatları dikkate alınarak her bir aday noktanın yatırım maliyeti belirlenmiştir. Daha sonra belirlenen on noktanın alanları dikkate alınarak kapasiteleri belirlenmiştir. Aday noktaların konumları gözetilerek her bir aday deponun hizmet verebileceği en fazla müşteri sayisı belirlenmiş ve Tablo 1'de verilmiştir. Çalışmada depo açma maliyeti için toplam yatırım bütçesi 1.200.000 TL olarak belirlenmiştir. Müşteri sayıs1 belirlenirken, bölgede yer alan eczane sayıları ve hastanelerin sayisı ile birlikte kapasiteleri dikkate alınmıştır.

Tablo 1. Aday nokta verileri

\begin{tabular}{ccccc}
\hline Aday & Depo & Yatırım Maliyeti (TL) & Kapasite (Koli) & Müşteri Sayısı \\
\hline \hline Aday-1: & Yolçatı & 350000 & 370 & 25 \\
Aday-2: & Beyciler & 225000 & 220 & 30 \\
Aday-3: & Bekirli & 120000 & 150 & 30 \\
Aday-4: & Sayalar & 98000 & 480 & 30 \\
Aday-5: & Sinekli & 250000 & 280 & 40 \\
Aday-6: & Akören & 190000 & 500 & 20 \\
Aday-7: & Büyükkılıçlı & 48000 & 150 & 30 \\
Aday-8: & Kavaklı & 750000 & 400 & 40 \\
Aday-9: & Alipaşa & 139000 & 200 & 30 \\
Aday-10: & Çanta & 440000 & 120 & 15 \\
\hline
\end{tabular}

Ele alınan problemde açılacak ecza depolarının hizmet verebileceği en fazla kurum sayılarının belirli olduğu varsayılmıştır. Bu bağlamda açılacak ecza depolarının en fazla 3 hastaneye, 10 sağlık ocağına ve 20 eczaneye hizmet verebileceği varsayılmıştır.

\subsubsection{Talep noktalarının belirlenmesi}

Problemde farklı yapılardaki talep noktaları belirlenirken, ilçede yer alan devlet / özel hastaneler, sağlık ocakları ve eczaneler dikkate alınmıştır. $\mathrm{Bu}$ doğrultuda toplam 5 hastane, 20 sağlık ocağ1 ve 47 eczane çalışmaya entegre edilmiştir.

\subsubsection{Hastaneler}

Ecza ürünlerinin en sik kullanıldığ $\breve{1}$ kurumların başında hastaneler gelmektedir. Hastayla birebir temas halinde olunan hastanelerde, ilaç tedariğinin hızlı ve etkin bir șekilde yapılması çok önemlidir. Bu bağlamda çalışma kapsamında ilçede bulunan beş hastane dikkate alınmıştır. Ecza depolarından hastanelere ilaç tedariğini gerçekleştirecek en uygun depo yeri belirlenmeye çalışılmıştır. Hastanelerin konumları Şekil 2'de gösterilmiştir.

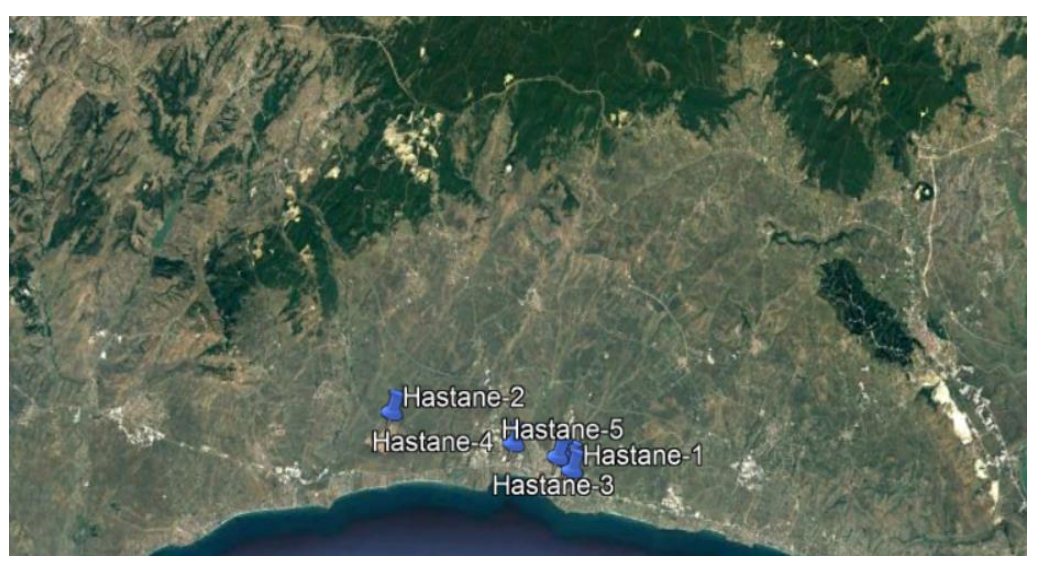

Şekil 2. İlçedeki hastane konumları

Hastane konumlarının belirlenmesinin ardından, aday noktalardan hastanelere olan mesafeleri ve geçiş süreleri hesaplanmış ve Tablo 2'de verilmiştir. 
Tablo 2. Aday depolar - hastaneler arasındaki geçiş süreleri ve mesafeler

\begin{tabular}{|c|c|c|c|c|c|c|c|c|c|c|}
\hline & \multicolumn{5}{|c|}{ Geçiş Süreleri (dk) } & \multicolumn{5}{|c|}{ Mesafeler (km) } \\
\hline & $\begin{array}{c}\text { Hastane } \\
1 \\
\end{array}$ & $\begin{array}{c}\text { Hastane } \\
2 \\
\end{array}$ & $\begin{array}{c}\text { Hastane } \\
\mathbf{3} \\
\end{array}$ & $\begin{array}{c}\text { Hastane } \\
4 \\
\end{array}$ & $\begin{array}{c}\text { Hastane } \\
5 \\
\end{array}$ & \begin{tabular}{|c|} 
Hastane \\
1 \\
\end{tabular} & $\begin{array}{c}\text { Hastane } \\
2 \\
\end{array}$ & $\begin{array}{c}\text { Hastane } \\
\mathbf{3} \\
\end{array}$ & $\begin{array}{c}\text { Hastane } \\
4 \\
\end{array}$ & $\begin{array}{c}\text { Hastane } \\
5 \\
\end{array}$ \\
\hline Aday 1 & 23 & 15 & 21 & 19 & 21 & 23 & 7 & 16 & 15 & 17 \\
\hline Aday 2 & 29 & 22 & 28 & 28 & 28 & 33 & 23 & 31 & 32 & 31 \\
\hline Aday 3 & 26 & 35 & 25 & 24 & 25 & 23 & 31 & 21 & 22 & 21 \\
\hline Aday 4 & 37 & 34 & 35 & 33 & 35 & 35 & 31 & 31 & 30 & 31 \\
\hline Aday 5 & 28 & 25 & 26 & 24 & 26 & 27 & 23 & 23 & 22 & 23 \\
\hline Aday 6 & 23 & 26 & 21 & 20 & 21 & 19 & 27 & 17 & 18 & 17 \\
\hline Aday 7 & 18 & 15 & 17 & 14 & 17 & 16 & 12 & 12 & 11 & 12 \\
\hline Aday 8 & 6 & 17 & 6 & 8 & 6 & 6 & 17 & 6 & 9 & 7 \\
\hline Aday 9 & 9 & 12 & 9 & 6 & 9 & 8 & 10 & 5 & 3 & 5 \\
\hline Aday 10 & 3 & 16 & 5 & 7 & 5 & 1 & 11 & 1 & 3 & 1 \\
\hline
\end{tabular}

Aday noktalardan hastanelere olan geçiş süreleri 3 $\mathrm{dk}$ ile $37 \mathrm{dk}$ arasında değişirken, aday noktalar ile hastaneler arasındaki mesafeler $1 \mathrm{~km}$ ile $35 \mathrm{~km}$ arasında değişmektedir. Örneğin Aday-1'den Hastane-1'e olan 23 km'lik mesafe 23 dk'da gidilebilirken, Aday-1'den Hastane 2'ye olan 7 km'lik mesafe $15 \mathrm{dk}$ sürmektedir. Bunun nedeni olarak ilçenin arazi ve yol yapısı gösterilebilir. Hastanelerin ecza ürünlerine olan talebi olarak yatak sayıları dikkate alınmıştır. Bu bağlamda, hastanelerin ecza ürünlerine olan talepleri koli bazında Tablo 3'teki gibidir.

Tablo 3 incelendiğinde, hastanelerin ecza ürünlerine olan talebi 30 koli ile 150 koli arasında değişmektedir. Hastaların aciliyet durumuna göre ihtiyaç duyulan ecza ürünlerinin hastanelere olabildiğince hızlı ulaştırılması gerekmektedir. Bu doğrultuda ele alınan problem için hastanelere en geç 20 dk' da ulaşılması gerektiği varsayılmıştır.
Tablo 3. Hastane talepleri

\begin{tabular}{cc}
\hline Hastane & Talep (Koli) \\
\hline \hline Hastane-1 & 51 \\
Hastane-2 & 30 \\
Hastane-3 & 150 \\
Hastane-4 & 115 \\
Hastane-5 & 110 \\
\hline
\end{tabular}

\subsubsection{Sağllk ocakları}

İnsanların temel sağlık hizmetlerinden kolaylıkla yararlanabildiği sağlık ocaklarında, ecza ürünlerine olan talep oldukça yüksektir. Bu bağlamda ilçede bulunan 20 sağlık ocağı talep noktası olarak çalışmaya entegre edilmiştir. Sağlık ocaklarının konumları Şekil 3'te verilmiştir.

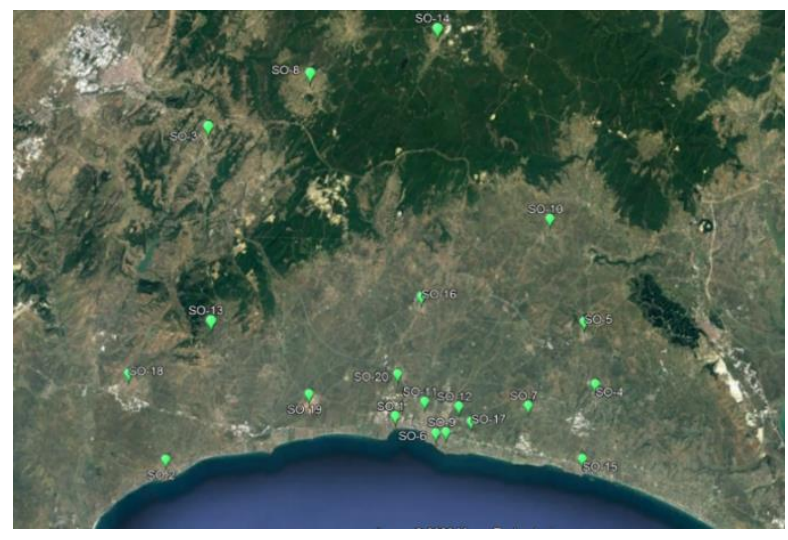

Şekil 3. İlçedeki sağlık ocakları konumları

Şekil 3'e bakıldığında, hemen hemen her bölgede yer alan sağlık ocaklarının ilçenin merkezinde daha fazla olduğu görülmektedir. Oldukça geniş bir alana yayılan sağlık ocaklarının aday noktalarla arasındaki geçiş süreleri Tablo 4'te gösterilirken, bu noktalar arasındaki mesafeler ise Tablo 5'te verilmişsir. 
Tablo 4. Aday noktalar-sağlik ocakları arası geçiş süreleri (dk)

\begin{tabular}{ccccccccccccccccccccc}
\hline Sağlık Ocă̆ı & $\mathbf{1}$ & $\mathbf{2}$ & $\mathbf{3}$ & $\mathbf{4}$ & $\mathbf{5}$ & $\mathbf{6}$ & $\mathbf{7}$ & $\mathbf{8}$ & $\mathbf{9}$ & $\mathbf{1 0}$ & $\mathbf{1 1}$ & $\mathbf{1 2}$ & $\mathbf{1 3}$ & $\mathbf{1 4}$ & $\mathbf{1 5}$ & $\mathbf{1 6}$ & $\mathbf{1 7}$ & $\mathbf{1 8}$ & $\mathbf{1 9}$ & $\mathbf{2 0}$ \\
\hline \hline Aday-1 & 19 & 15 & 16 & 35 & 31 & 23 & 28 & 25 & 25 & 29 & 17 & 22 & 14 & 28 & 31 & 15 & 25 & 19 & 17 & 14 \\
Aday-2 & 26 & 26 & 13 & 38 & 37 & 29 & 35 & 10 & 32 & 36 & 25 & 27 & 24 & 20 & 33 & 22 & 32 & 25 & 24 & 24 \\
Aday-3 & 23 & 35 & 38 & 30 & 25 & 26 & 25 & 34 & 29 & 7 & 22 & 24 & 35 & 27 & 32 & 18 & 29 & 40 & 33 & 25 \\
Aday-4 & 33 & 39 & 24 & 48 & 42 & 37 & 42 & 6 & 39 & 38 & 31 & 36 & 37 & 12 & 46 & 26 & 39 & 38 & 36 & 28 \\
Aday-5 & 24 & 30 & 19 & 37 & 31 & 28 & 30 & 11 & 30 & 25 & 22 & 27 & 29 & 9 & 37 & 15 & 30 & 30 & 27 & 19 \\
Aday-6 & 19 & 31 & 34 & 26 & 19 & 22 & 20 & 37 & 25 & 1 & 18 & 20 & 31 & 30 & 28 & 18 & 25 & 37 & 29 & 24 \\
Aday-7 & 15 & 20 & 24 & 30 & 25 & 18 & 23 & 18 & 21 & 22 & 13 & 17 & 19 & 22 & 26 & 9 & 20 & 25 & 17 & 9 \\
Aday-8 & 7 & 19 & 30 & 12 & 13 & 9 & 6 & 36 & 9 & 25 & 9 & 7 & 19 & 40 & 9 & 20 & 5 & 25 & 19 & 14 \\
Aday-9 & 6 & 14 & 26 & 21 & 22 & 9 & 15 & 25 & 12 & 22 & 4 & 9 & 14 & 28 & 18 & 8 & 12 & 20 & 14 & 2 \\
Aday-10 & 4 & 18 & 27 & 17 & 19 & 1 & 11 & 34 & 3 & 23 & 7 & 4 & 18 & 38 & 14 & 18 & 6 & 23 & 18 & 12 \\
\hline
\end{tabular}

Tablo 5. Aday noktalar-sağlık ocakları arası geçiş mesafeleri $(\mathrm{km})$

\begin{tabular}{ccccccccccccccccccccc}
\hline Sağlık Ocă̆ı & $\mathbf{1}$ & $\mathbf{2}$ & $\mathbf{3}$ & $\mathbf{4}$ & $\mathbf{5}$ & $\mathbf{6}$ & $\mathbf{7}$ & $\mathbf{8}$ & $\mathbf{9}$ & $\mathbf{1 0}$ & $\mathbf{1 1}$ & $\mathbf{1 2}$ & $\mathbf{1 3}$ & $\mathbf{1 4}$ & $\mathbf{1 5}$ & $\mathbf{1 6}$ & $\mathbf{1 7}$ & $\mathbf{1 8}$ & $\mathbf{1 9}$ & $\mathbf{2 0}$ \\
\hline \hline Aday-1 & 16 & 15 & 15 & 31 & 24 & 19 & 27 & 23 & 20 & 26 & 15 & 17 & 11 & 28 & 30 & 13 & 21 & 18 & 8 & 11 \\
Aday-2 & 31 & 29 & 11 & 45 & 39 & 32 & 40 & 7 & 33 & 32 & 30 & 31 & 24 & 19 & 42 & 19 & 34 & 25 & 24 & 21 \\
Aday-3 & 21 & 41 & 43 & 25 & 19 & 22 & 21 & 22 & 23 & 5 & 20 & 21 & 38 & 19 & 33 & 13 & 24 & 45 & 32 & 18 \\
Aday-4 & 32 & 40 & 20 & 40 & 35 & 33 & 36 & 5 & 34 & 33 & 29 & 31 & 39 & 8 & 45 & 24 & 35 & 39 & 31 & 26 \\
Aday-5 & 23 & 32 & 18 & 31 & 27 & 25 & 27 & 10 & 26 & 23 & 21 & 23 & 29 & 10 & 37 & 13 & 27 & 32 & 23 & 18 \\
Aday-6 & 17 & 37 & 39 & 14 & 9 & 18 & 17 & 34 & 19 & 1 & 16 & 17 & 31 & 28 & 29 & 14 & 20 & 41 & 28 & 20 \\
Aday-7 & 12 & 21 & 23 & 27 & 17 & 14 & 22 & 16 & 15 & 19 & 10 & 12 & 18 & 21 & 26 & 5 & 16 & 26 & 12 & 7 \\
Aday-8 & 8 & 25 & 36 & 8 & 10 & 7 & 4 & 36 & 7 & 24 & 9 & 6 & 21 & 41 & 5 & 18 & 5 & 29 & 17 & 13 \\
Aday-9 & 5 & 18 & 32 & 19 & 18 & 7 & 15 & 23 & 8 & 19 & 3 & 5 & 15 & 28 & 18 & 6 & 9 & 22 & 11 & 1 \\
Aday-10 & 1 & 19 & 31 & 13 & 13 & 1 & 8 & 29 & 1 & 18 & 3 & 1 & 16 & 34 & 12 & 11 & 3 & 24 & 12 & 7 \\
\hline
\end{tabular}

Tablo 4 ve Tablo 5'e odaklanıldığında, aday noktalardan sağlık ocaklarına olan geçiş süreleri 1 $\mathrm{dk}$ ile $48 \mathrm{dk}$ arasında değişirken, aday noktalar ile eczaneler arasındaki mesafeler $1 \mathrm{~km}$ ile $45 \mathrm{~km}$ arasında değişmektedir. Örneğin Aday-1'den Sağlik Ocağı-1'e olan 16 km'lik mesafe, 19 dk'da gidilebilmektedir. Mesafelerin ve geçiş sürelerinin belirlenmesinin ardından sağlık ocaklarının ecza ürünlerine olan talepleri belirlenmiştir. Talepler belirlenirken sağlık ocağının yer aldığı mahalle nüfusu ve mahallede yer alan sağlı ocağı sayısı dikkate alınmıştır. Bu bağlamda, sağlık ocaklarının ecza ürünlerine olan talepleri koli bazında Tablo 6 'daki gibidir.

Tablo 6. Sağlık ocağı talepleri

\begin{tabular}{cccc}
\hline Sağlık Ocă̆ı (SO) & Talep (Koli) & Sağlık Ocă̆ı (SO) & Talep (Koli) \\
\hline \hline SO-1 & 9 & SO-11 & 29 \\
SO-2 & 16 & SO-12 & 35 \\
SO-3 & 6 & SO-13 & 6 \\
SO-4 & 8 & SO-14 & 2 \\
SO-5 & 3 & SO-15 & 39 \\
SO-6 & 9 & SO-16 & 3 \\
SO-7 & 4 & SO-17 & 35 \\
SO-8 & 3 & SO-18 & 6 \\
SO-9 & 14 & SO-19 & 54 \\
SO-10 & 3 & SO-20 & 2 \\
\hline
\end{tabular}

Sağlık ocakların ecza ürünlerine olan talebi 2 koli ile 54 koli arasında değişmektedir. Toplam 286 koli talebi olan sağlık ocaklarına ecza ürünlerinin en geç 25 dk' da ulaştırılması gerektiği varsayılmıştır. 


\subsubsection{Eczaneler}

İnsanların ecza ürünlerini temin ettiği kurumların başında eczaneler gelmektedir. Eczaneler, tedarik ağı içerisinde ecza depolarının başlıca müşterileri arasındadır. $\mathrm{Bu}$ bağlamda, ilçede yer alan 47 eczane talep noktası olarak çalışmaya dahil edilmiştir. İlçede yer alan eczanelerin konumları Şekil 4'te gösterilmiştir.

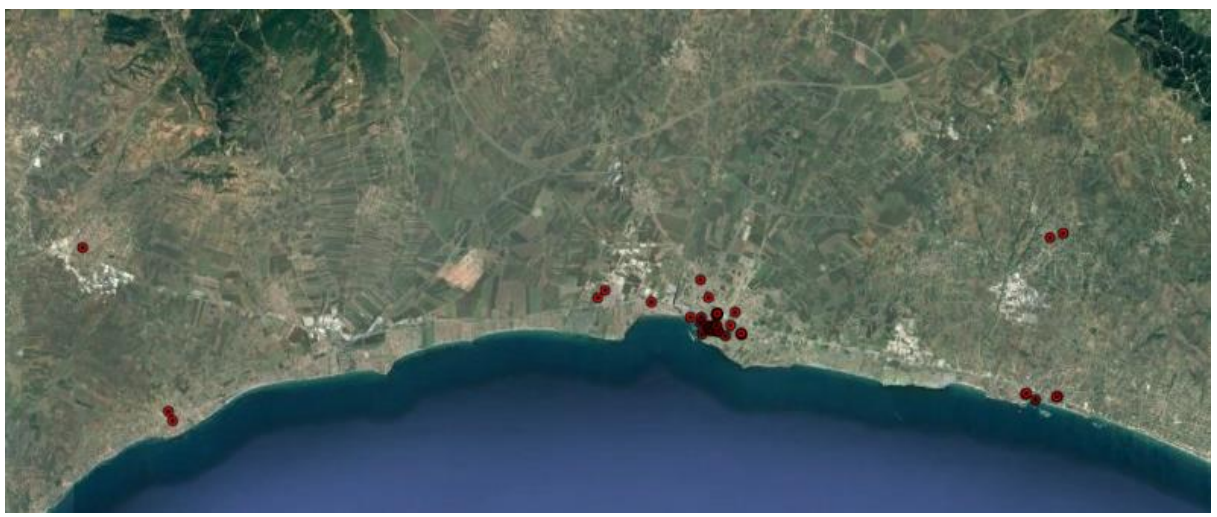

Şekil 4. İlçedeki eczane konumları

Eczanelerin talepleri belirlenirken, eczanenin bulunduğu mahalle nüfusu, mahallede bulunan eczane sayısı ve eczanenin hastaneye yakın olma durumu dikkate alınmıştır. İlçede yer alan eczanelerin talepleri Tablo 7'deki gibidir.

Tablo 7. Eczane talepleri

\begin{tabular}{|c|c|c|c|c|c|c|c|}
\hline $\begin{array}{c}\text { Eczane } \\
(\mathbf{E})\end{array}$ & $\begin{array}{l}\text { Talep } \\
\text { (Koli) } \\
\end{array}$ & $\begin{array}{c}\text { Eczane } \\
(\mathbf{E})\end{array}$ & $\begin{array}{l}\text { Talep } \\
\text { (Koli) } \\
\end{array}$ & $\begin{array}{c}\text { Eczane } \\
(\mathrm{E})\end{array}$ & $\begin{array}{l}\text { Talep } \\
\text { (Koli) } \\
\end{array}$ & $\begin{array}{c}\text { Eczane } \\
(\mathrm{E})\end{array}$ & $\begin{array}{l}\text { Talep } \\
\text { (Koli) } \\
\end{array}$ \\
\hline E-1 & 12 & E-13 & 2 & E-25 & 11 & E-37 & 5 \\
\hline E-2 & 2 & E-14 & 10 & E-26 & 2 & E-38 & 5 \\
\hline E-3 & 5 & E-15 & 15 & E-27 & 9 & E-39 & 13 \\
\hline E-4 & 9 & E-16 & 1 & E-28 & 1 & E-40 & 2 \\
\hline E-5 & 3 & E-17 & 3 & E-29 & 4 & E-41 & 21 \\
\hline E-6 & 6 & E-18 & 4 & E-30 & 18 & E-42 & 2 \\
\hline E-7 & 7 & E-19 & 9 & E-31 & 11 & E-43 & 3 \\
\hline E-8 & 5 & E-20 & 9 & E-32 & 5 & E-44 & 12 \\
\hline E-9 & 3 & E-21 & 5 & E-33 & 12 & E-45 & 12 \\
\hline E-10 & 9 & E-22 & 10 & E-34 & 5 & E-46 & 7 \\
\hline E-11 & 18 & E-23 & 5 & E-35 & 2 & E-47 & 13 \\
\hline E-12 & 12 & E-24 & 2 & E-36 & 6 & & \\
\hline
\end{tabular}

Tablo 7'ye göre eczanelerin ecza ürünlerine olan talebinin 2 koli ile 18 koli arasında değiştiği görülmektedir. Toplam 347 koli talebi olan eczanelere, ecza ürünlerinin en geç $30 \mathrm{dk}$ 'da ulaştırılması gerektiği varsayılmıştır.

\subsection{Matematiksel model sonuçları}

Çalışma kapsamında belirlenen veriler kullanılarak önerilen matematiksel model çalıştırıldığında elde edilen sonuçlar aşağıdaki gibidir.
Önerilen matematiksel modele göre minimum mesafeyi verecek en uygun 4 depo yeri belirlenmiş̧ir. Buna göre dört depo yerinden talep noktalarına toplam dağıtım mesafesi $714 \mathrm{~km}$ olarak bulunmuştur. Aday-6 (Akören), Aday-7 (Büyükkılıçl1), Aday-8 (Kavaklı) ve Aday-9 (Alipaşa) en uygun depo yerleri olarak belirlenmiştir. Önerilen matematiksel modele göre açılmasına karar verilen depo konumları Şekil 5'te gösterilmiştir. 


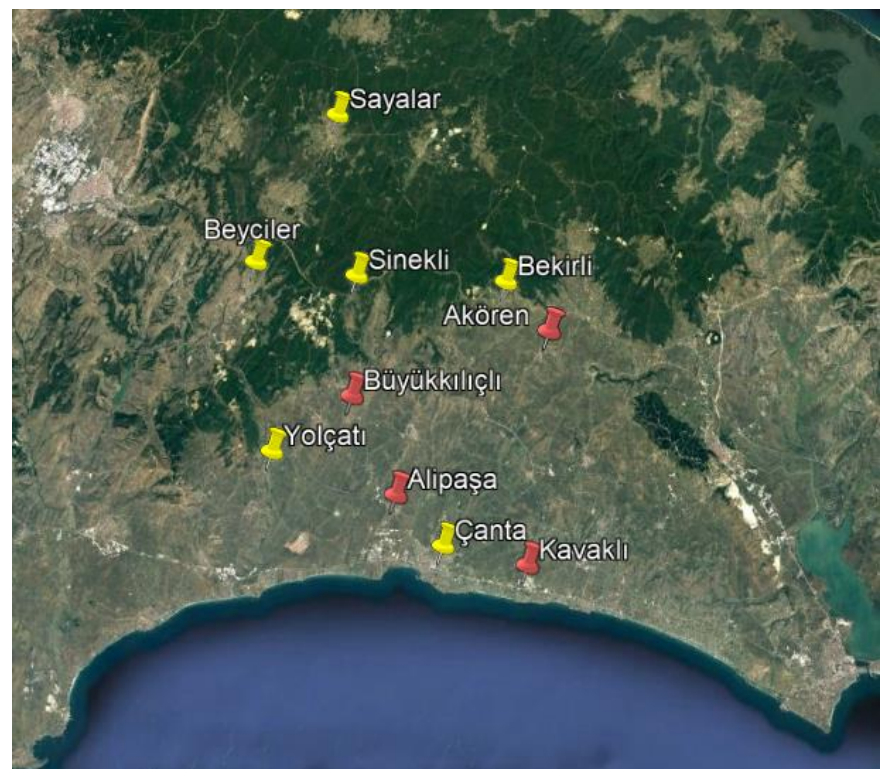

Şekil 5. Açılacak depo yerleri

Şekil 5'ten görüleceği üzere açılacak depolar kırmızı ile gösterilmiştir. Depolar; eczane, sağlık ocağ 1 ve hastanelerin yoğun olarak bulunduğu şehir merkezine yakın konumlarda yer almaktadır. Matematiksel model sonucunda hastanelerin hangi depolardan, ne kadar sürede hizmet alacağı Tablo 8 'de gösterilmiştir.

Tablo 8'e bakıldığında açılacak depolardan hastanelere ecza ürünlerinin ulaştırılma süreleri 6 $\mathrm{dk}$ ile $20 \mathrm{dk}$ arasında değişmektedir. Kavaklı'dan iki hastanenin talebi karşılanırken, diğer 3 depodan birer hastanenin talebi karşılanmaktadır.
Tablo 8. Hastane-açılacak depo arası geçiş süreleri

\begin{tabular}{lll}
\hline Hastane (H) & Depo & Süre (dk) \\
\hline \hline H-1 & Kavaklı & 6 \\
H-2 & Alipaşa & 12 \\
H-3 & Kavaklı & 6 \\
H-4 & Akören & 20 \\
H-5 & Büyükk1lıçlı & 17 \\
\hline
\end{tabular}

Ele alınan problemde bir diğer talep noktası olan sağlık ocaklarına bakıldığında, matematiksel model sonuçlarına göre sağlik ocaklarının hangi depodan ne kadar sürede hizmet alacağı Tablo 9'da gösterilmiştir.

Tablo 9. Açılacak depo-sağlık ocağı arasındaki geçiş süreleri

\begin{tabular}{|ll|l|ll|l|}
\hline Depo & Sağlık Ocağı (SO) & Süre (dk) & Depo & Sağlık Ocağı (SO) & Süre (dk) \\
\hline \hline \multirow{5}{*}{ Akören } & SO-5 & 19 & & SO-2 & 20 \\
& SO-9 & 25 & & SO-3 & 24 \\
& SO-10 & 1 & Büyükkılıçli & SO-8 & 18 \\
& SO-11 & 18 & & SO-13 & 19 \\
& SO-12 & 20 & & SO-14 & 22 \\
\cline { 2 - 3 } KO-17 & 25 & & SO-1 & 14 \\
& SO-4 & 12 & Alipaşa & SO-16 & 12 \\
& SO-6 & 9 & & SO-18 & 20 \\
& SO-7 & 6 & & SO-19 & 14 \\
& SO-15 & 9 & & SO-20 & 2 \\
\hline
\end{tabular}

Tablo 9'a göre Akören'de yer alan ecza deposu 6 sağlik ocağına $1 \mathrm{dk}$ ile $25 \mathrm{dk}$ arasında değişen sürelerde hizmet vermektedir. Kavaklı'da yer alan depo 4 sağlık ocağına, Büyükkılıçlı'da yer alan depo 5 sağlık ocağına ve son olarak Alipaşa'da yer alan depo 5 sağlık ocağına hizmet vermektedir.
Ele alınan problemde son talep noktası olarak eczaneler dikkate alınmıştır. Matematiksel model sonuçlarına göre eczanelerin hangi depodan ne kadar sürede hizmet alacağı Tablo $10^{\prime}$ da gösterilmiştir. 
Tablo 10. Açılacak depo-eczane arasındaki geçiş süreleri

\begin{tabular}{|c|c|c|c|c|c|c|c|c|}
\hline Depo & Eczane & Süre (dk) & Depo & Eczane & Süre (dk) & Depo & Eczane & Süre (dk) \\
\hline \multirow{21}{*}{ Akören } & E-10 & 24 & \multirow{18}{*}{ Alipaşa } & E-2 & 11 & Büyükk1lıçlı & E-7 & 16 \\
\hline & E-15 & 18 & & E-4 & 9 & \multirow{20}{*}{ Kavakl1 } & E-1 & 10 \\
\hline & E-25 & 22 & & E-5 & 10 & & E-3 & 12 \\
\hline & E-30 & 22 & & E-6 & 10 & & E-9 & 13 \\
\hline & E-33 & 23 & & E-8 & 11 & & E-12 & 18 \\
\hline & E-41 & 24 & & E-11 & 5 & & E-18 & 12 \\
\hline & E-46 & 26 & & E-13 & 10 & & E-21 & 9 \\
\hline & E-47 & 23 & & E-14 & 9 & & E-22 & 5 \\
\hline & & & & E-16 & 19 & & E-23 & 9 \\
\hline & & & & E-17 & 7 & & E-26 & 10 \\
\hline & & & & E-19 & 9 & & E-27 & 8 \\
\hline & & & & E-20 & 9 & & E-28 & 22 \\
\hline & & & & E-24 & 15 & & E-29 & 11 \\
\hline & & & & E-32 & 8 & & E-31 & 10 \\
\hline & & & & E-37 & 8 & & E-34 & 12 \\
\hline & & & & E-40 & 8 & & E-35 & 9 \\
\hline & & & & E-42 & 10 & & E-36 & 7 \\
\hline & & & & E-43 & 11 & & E-38 & 7 \\
\hline & & & & & & & E-39 & 16 \\
\hline & & & & & & & E-44 & 16 \\
\hline & & & & & & & E-45 & 16 \\
\hline
\end{tabular}

Tablo 10'a göre Akören'de yer alan ecza deposu 8 eczaneye, Alipaşa'da yer alan depo 18 eczaneye, Büyükkılıçlı'da yer alan depo 1 eczaneye ve son olarak Kavaklı'da yer alan depo 20 eczaneye hizmet vermektedir. Eczanelere ulaşım süreleri 5 ile 26 dakika arasında değişmektedir.

\subsection{Duyarlılık analizi}

Çalışmada önerilen yöntemin sonuçlarını analiz etmek ve doğruluğunu göstermek amaciyla duyarlılık analizi yapılmıştır. Yöntemin değişikliklere karşı hassasiyetini ölçmek amacıyla modelde kullanılan bazı parametre değerleri değiştirilerek sonuçlar incelenmiştir.

\subsubsection{Bütçe analizi}

Probleme yönelik hazırlanan matematiksel modelin etkinliğini test etmek amaciyla, duyarlılık analizi kapsamında ilk olarak kullanılabilir bütçe değiştirilmiş ve elde edilen amaç fonksiyon değerleri ile birlikte açılma kararı verilen aday depolar Tablo 11'de verilmiştir.

İlk olarak mevcut durumdaki bütçe 1.200.000 TL'den 1.100.000 TL'ye düşürülmüştür. $\mathrm{Bu}$ durumda matematiksel model uygun çözüm üretememiştir. Daha sonra proje bütçesi 1.300.000 TL'ye artırılmış ve çözümler incelenmiştir.
Tablo 11. Bütçe analizi sonuçları

\begin{tabular}{lll}
\hline Bütçe (TL) & Z* & Açılan Depolar \\
\hline \hline 1100000 & Çözüm Yok & - \\
1200000 & 714 & $6-7-8-9$ \\
1300000 & 695 & $1-7-8-9$ \\
1400000 & 695 & $1-7-8-9$ \\
1500000 & 695 & $1-7-8-9$ \\
Sinırs1z & 695 & $1-7-8-9$ \\
\hline
\end{tabular}

Bu durumda amaç fonksiyon değeri 695 olmuştur. Bütçedeki bu 100.000 TL'lik artış toplam dağıtım mesafesinde 19 birimlik bir iyileştirme sağlamıştır. Analizin diğer aşamaları için bütçe $100.000 \mathrm{TL}$ artırıldığında amaç fonksiyon değerinde iyileşme olmadığı görülmüştür.

\subsubsection{Açılacak depo sayısı analizi}

Duyarlılık analizi kapsamında açılacak depo sayısı değiştirilmiş ve elde edilen amaç fonksiyon değerleri ile birlikte açılma kararı verilen aday depolar Tablo 12'de verilmiştir.

Tablo 12'den görüleceği üzere açılacak depo sayısı artırıldığında matematiksel modelin her adımda daha kötü sonuç vermektedir. Bunun nedeni olarak modelde bulunan bütçe kısıtı gösterilebilir. 
Tablo 12. Depo sayısı analizi sonuçları

\begin{tabular}{lll}
\hline Depo Sayısı & Z $^{*}$ & Açılan Depolar \\
\hline \hline 4 & 714 & $6-7-8-9$ \\
5 & 1282 & $1-6-7-9-10$ \\
6 & 1091 & $2-3-6-7-9-10$ \\
7 & Çözüm Yok & - \\
3 & Çözüm Yok & - \\
\hline
\end{tabular}

Buna ek olarak bütçe kısıtı kaldırıldığında farklı tesis sayıları için elde edilen sonuçlar Tablo 13'te verilmiştir.

Tablo 13. Bütçeden bağımsız depo sayısı analizi sonuçları

\begin{tabular}{cll}
\hline $\begin{array}{c}\text { Depo } \\
\text { Sayısı }\end{array}$ & \multicolumn{1}{c}{$\mathbf{Z}^{*}$} & \multicolumn{1}{c}{ Açılan Depolar } \\
\hline \hline 1 & Çözüm Yok & - \\
2 & Çözüm Yok & - \\
3 & Çözüm Yok & - \\
4 & 695 & $1-7-8-9$ \\
5 & 511 & $1-7-8-9-10$ \\
6 & 447 & $1-6-7-8-9-10$ \\
7 & 420 & $1-4-6-7-8-9-10$ \\
8 & 416 & $1-2-4-6-7-8-9-10$ \\
9 & 416 & $1-2-3-4-6-7-8-9-10$ \\
10 & 416 & $1-2-3-4-5-6-7-8-9-10$ \\
\hline
\end{tabular}

Matematiksel model tesis sayıs 1,2 ve 3 iken uygun çözüm vermemektedir. Tesis sayısı 4'ten 8'e kadar artırıldığında her adımda amaç fonksiyonu değerinin iyileştiği görülmektedir.

\subsubsection{En geç ulaşım süresi analizi}

Duyarlılık analizi kapsamında ecza ürünlerinin açılacak depolardan talep noktalarına en geç ulaşım süreleri değiştirilmiş ve elde edilen amaç fonksiyon değerleri ile birlikte açılma kararı verilen aday depolar Tablo 14'te verilmiştir.

Tablo 14. Değişen ulaşım sürelerine göre amaç fonksiyonu

\begin{tabular}{lll}
\hline $\begin{array}{l}\text { Ulaşım } \\
\text { (dk) }\end{array}$ & Süresi & $\begin{array}{l}\text { Açılan } \\
\text { Depolar }\end{array}$ \\
\hline \hline Mevcut Durum & 714 & $6-7-8-9$ \\
20 & Çözüm Yok & - \\
25 & 619 & $6-7-8-9$ \\
30 & 616 & $6-7-8-9$ \\
Sinırsız & 616 & $6-7-8-9$ \\
\hline
\end{tabular}

Yapılan analizde ilk olarak her bir talep noktasina 20 dk'da varılması gerektiği varsayılmıştır. Önerilen matematiksel model bu durum için uygun bir çözüm üretememiştir. Daha sonra en geç ulaşım süreleri her bir nokta için $25 \mathrm{dk}$ yapılmış ve amaç fonksiyon değeri 619 olarak hesaplanmıştır. Üçüncü adımda en geç ulaşım süreleri $30 \mathrm{dk}$ yapıldığında amaç fonksiyon değeri 616 olarak bulunmuştur. Son olarak en geç varış süresi ile ilgili kısıt kaldırıldığında amaç fonksiyon değeri 616 olarak bulunmuştur.

\subsubsection{Kapasite analizi}

Duyarlılık analizi kapsamında son olarak aday ecza depolarının kapasiteleri değiştirilmiş ve elde edilen amaç fonksiyon değerleri ile birlikte açılma kararı verilen aday depolar Tablo 15'te verilmiştir.

Tablo 15. Kapasite analizi

\begin{tabular}{ccc}
\hline Kapasite & $\mathbf{Z}^{*}$ & Açılan Depolar \\
\hline \hline Mevcut Durum & 714 & $6-7-8-9$ \\
300 & 625 & $6-7-8-9$ \\
400 & 578 & $3-7-8-9$ \\
500 & 569 & $4-7-8-9$ \\
Sinırsiz & 568 & $4-7-8-9$ \\
\hline
\end{tabular}

Analiz kapsamında ilk olarak her bir deponun kapasitesinin 300 koli olduğu varsayılmış daha sonra kapasite miktarının 400 ve 500 koli olduğu durumlar için sonuçlar elde edilmiştir. Depo kapasitesinin artırılması ile birlikte amaç fonksiyon değeri sürekli iyileşerek 569 değerine ulaşmıştır. Son olarak ilgili kısıt kaldırıldığında 568 değeri elde edilmiştir.

Yapılan duyarlılık analizi kapsamında 4 farklı başlıkta 23 farklı model koşturularak sonuçlar elde edilmiştir. Çalışma kapsamında incelenen senaryolar her birinde önerilen matematiksel model başarılı sonuçlar vermiştir. Dikkate alınan nokta sayısı arttığ1 taktirde model çözüm üretemezse, sezgisel ya da metasezgisel algoritmalara başvurulabilir.

\section{Sonuç}

Çalışmada ecza ürünlerinin dağıtımını içeren tedarik ağında, farklı yapılardaki talep noktaları için ecza deposu yeri seçim problemi ele alınmıştır. Bu bağlamda farklı yapıdaki talep noktaları olarak hastaneler, sağlık ocakları ve eczaneler belirlenmiştir. Talep noktalarının belirlenmesinin ardından, problem kapasiteli tesis yeri seçim 
problemi olarak ele alınmış ve probleme yönelik yeni bir matematiksel model önerilmiştir. Uygulama bölgesi olarak İstanbul/Silivri ilçesi seçilmiştir. Her bir noktanın talebi, noktanın konumu gözetilerek belirlenmiştir. Uzmanlarla görüşülerek beş hastane, yirmi sağlık ocağı ve kırk yedi eczane olmak üzere, her bir talep noktasına ulaşılabilecek en geç süreler belirlenmiştir. Çalışmanın devamında; önerilen matematiksel model kullanılarak minimum mesafeyle dağıtım yapılması için açılması gereken ecza depolarının yerleri belirlenmiştir. Modelin sonuçlarını analiz etmek ve doğruluğunu göstermek amaciyla problemde kullanılan parametre değerleri değiştirilerek duyarlılık analizi yapılmıştır.

Çalışmanın literatüre katkısı şu şekilde tanımlanabilir: (1) Ecza deposu yer seçim problemi ele alınmıştır; (2) Problemde hastaneler, sağlık ocakları ve eczaneler dikkate alınmıştır; (3) Problem kapasiteli tesis yeri seçim problemi olarak ele alınmış ve buna yönelik yeni bir matematiksel model önerilmiştir; (4) Aday depo yerleri belirlenirken, gerçek lokasyonlar kullanılmıştır; (5) Uzmanlarla görüşülerek her bir talep noktasına gönderilecek olan ecza ürünlerinin en geç ulaştırılması gereken süreleri belirlenmiştir; (6) Önerilen metodolojinin güvenilirliğini ve uygulanabilirliğini göstermek için gerçek bir uygulama ile çalışma pekiştirilmiştir; (7) Farklı senaryolar oluşturularak modelin esnekliği gösterilmiştir.

Sonraki çalışmalar için; farklı bölgeler ele alınabilir, çok ürünlü yapılar incelenebilir, dağıtım ağında rotalama planın oluşturulması dikkate alınabilir. Dağıtımda kullanılacak araçlar dikkate alınarak, probleme araç rotalama da dahil edilerek matematiksel model genişletilebilir. Daha çok sayıda dağıtım noktası dikkate alınarak matematiksel modelin çözümüne yönelik algoritmalar geliştirilebilir. Çalışmaya belirsizliklerin dahil edilebilmesi amaciyla ele alınan probleme bulanıklık, rassallık gibi belirsizlik içeren yaklaşımlar dahil edilebilir.

\section{Kaynaklar}

Arthur, J. L., Hachey, M., Sahr, K., Huso, M. and Kiester, A. R. (1997). Finding all optimal solutions to the reserve site selection problem: formulation and computational analysis. Environmental and Ecological Statistics, 4(2), 153-165, https://doi.org/10.1023/A:1018570311399.

Bahadori-Chinibelagh, S., Fathollahi-Fard, A. M. and Hajiaghaei-Keshteli, M. (2019). Two constructive algorithms to address a multi-depot home healthcare routing problem. IETE Journal of Research, 1-7, https://doi.org/10.1080/03772063.2019.1642802

Balinski, M. L. (1965). Integer programming: methods, uses, computations. Management Science, 12(3), 253-313, https://doi.org/10.1287/mnsc.12.3.253.

Chen, X., Yang, H. and Wang, X. (2019). Effects of price cap regulation on the pharmaceutical supply chain. Journal of Business Research, 97, 281-290,

https://doi.org/10.1016/j.jbusres.2018.01.030.

Friemann, F. and Schönsleben, P. (2016). Reducing global supply chain risk exposure of pharmaceutical companies by further incorporating warehouse capacity planning into the strategic supply chain planning process. Journal of Pharmaceutical Innovation, 11(2), 162-176, https://doi.org/10.1007/s12247-0169249-6.

Haial, A., Berrado, A. and Benabbou, L. (2019). Redesigning a transportation network: the case of a pharmaceutical supply chain. International Journal of Logistics Systems and Management, 35(1), 90-118, https://doi.org/10.1504/IJLSM.2020.10025514.

Haight, R. G., Revelle, C. S. and Snyder, S. A. (2000). An integer optimization approach to a probabilistic reserve site selection problem. Operations Research, 48(5), 697-708, https://doi.org/10.1287/opre.48.5.697.12411.

Jelokhani-Niaraki, M. and Malczewski, J. (2015). Decision complexity and consensus in webbased spatial decision making: a case study of site selection problem using gis and multicriteria analysis. Cities, 45, 60-70, https://doi.org/10.1016/j.cities.2015.03.007.

Ji, Y. (2019). Optimal scheduling in home health care: pharmacy-hospital-patient's vehicle routing problem. In Proceedings of the 3rd International Conference on Computer Science and Application Engineering (pp. 1-6), https://doi.org/10.1145/3331453.3361310.

Koc, A., Turk, S. and Şahin, G. (2019). Multi-criteria of wind-solar site selection problem using a gis-ahp based approach with an application in Igdir province/Turkey. Environmental Science and Pollution Research, 26(31), 32298-32310, https://doi.org/10.1007/s11356-019-06260-1.

Li, X., He, J. and Liu, X. (2009). Intelligent gis for solving high-dimensional site selection problems using ant colony optimization techniques. International Journal of Geographical Information Science, 23(4), 399-416, https://doi.org/10.1080/13658810801918491. 
Lin, M., Huang, C. and Xu, Z. (2020). MULTIMOORA based mcdm model for site selection of car sharing station under picture fuzzy environment. Sustainable Cities and Society, 53, 101873, https://doi.org/10.1016/j.scs.2019.101873.

Lubis, A. and Mawengkang, H. (2020). A capacitated heterogeneous vehicle routing problem for pharmaceutical products delivery. Systematic Reviews in Pharmacy, 11(4), 738-741.

Masoumi, A. H., Yu, M. and Nagurney, A. (2012). A supply chain generalized network oligopoly model for pharmaceuticals under brand differentiation and perishability. Transportation Research Part E: Logistics and Transportation Review, 48(4), 762-780, https://doi.org/10.1016/j.tre.2012.01.001.

Myerson, A. S., Krumme, M., Nasr, M., Thomas, H. and Braatz, R. D. (2015). Control systems engineering in continuous pharmaceutical manufacturing. 2014 Continuous Manufacturing Symposium. Journal of Pharmaceutical Sciences, $\quad$ 104(3), 832-839, https://doi.org/10.1002/jps.24311.

Nematollahi, M., Hosseini-Motlagh, S. M. and Heydari, J. (2017). Economic and social collaborative decision-making on visit interval and service level in a two-echelon pharmaceutical supply chain. Journal of Cleaner Production, 142, 39563969 ,

https://doi.org/10.1016/j.jclepro.2016.10.062.

Oufella, S. and Hamdadou, D. (2018). A collaborative spatial decision support system applied to site selection problems. International Journal of Applied Management Science, 10(2), 127-156, https://doi.org/10.1504/IJAMS.2018.092078.

Papageorgiou, L. G., Rotstein, G. E. and Shah, N. (2001). Strategic supply chain optimization for the pharmaceutical industries. Industrial \& Engineering Chemistry Research, 40(1), 275286, https://doi.org/10.1021/ie990870t.

Pedroso, M. C. and Nakano, D. (2009). Knowledge and information flows in supply chains: a study on pharmaceutical companies. International Journal of Production Economics, 122(1), 376384, https://doi.org/10.1016/j.ijpe.2009.06.012.

Redi, A. A. N. P., Maula, F. R., Kumari, F., Syaveyenda, N. U., Ruswandi, N., Khasanah, A. U. and Kurniawan, A. C. (2020). Simulated annealing algorithm for solving the capacitated vehicle routing problem: a case study of pharmaceutical distribution. Jurnal Sistem dan Manajemen Industri, $\quad 4(1), \quad 41-49$, https://doi.org/10.30656/jsmi.v4i1.2215.

Rossetti, C. L., Handfield, R. and Dooley, K. J. (2011). Forces, trends, and decisions in pharmaceutical supply chain management. International Journal of Physical Distribution \& Logistics Management, 41(6), 601-622, https://doi.org/10.1108/09600031111147835.

Shah, N. (2004). Pharmaceutical supply chains: key issues and strategies for optimisation. Computers \& Chemical Engineering, 28(6-7), 929-941, https://doi.org/10.1016/j.compchemeng.2003.09 .022 .

Uthayakumar, R. and Priyan, S. (2013). Pharmaceutical supply chain and inventory management strategies: optimization for a pharmaceutical company and a hospital. Operations Research for Health Care, 2(3), 52-64, https://doi.org/10.1016/j.orhc.2013.08.001.

Weraikat, D., Zanjani, M. K., and Lehoux, N., (2016). Coordinating a green reverse supply chain in pharmaceutical sector by negotiation. Computers \& Industrial Engineering, 93, 67-77, https://doi.org/10.1016/j.cie.2015.12.026.

Wong, C. K., Fung, I. W. H. and Tam, C. M. (2010). Comparison of using mixed-integer programming and genetic algorithms for construction site facility layout planning. Journal Of Construction Engineering And Management, 136(10), 1116-1128, https://doi.org/10.1061/(ASCE)CO.19437862.0000214

Wu, Y., Zhang, B., Wu, C., Zhang, T. and Liu, F. (2019). Optimal site selection for parabolic trough concentrating solar power plant using extended PROMETHEE method: a case in China. Renewable Energy, https://doi.org/10.1016/j.renene.2019.05.131.

Yap, J. Y. L., Ho, C. C. and Ting, C. Y. (2019). A systematic review of the applications of multicriteria decision-making methods in site selection problems. Built Environment Project and Asset Management, https://doi.org/10.1108/BEPAM-05-2018-0078.

Yu, X., Li, C., Shi, Y. and Yu, M. (2010). Pharmaceutical supply chain in China: current issues and implications for health system reform. Health Policy, 97(1), 8-15, https://doi.org/10.1016/j.healthpol.2010.02.010.

Zahiri, B., Jula, P. and Tavakkoli-Moghaddam, R. (2018). Design of a pharmaceutical supply chain network under uncertainty considering perishability and substitutability of products. Information Sciences, 423, 257-283, https://doi.org/10.1016/j.ins.2017.09.046. 